\title{
Artificial Accelerated Ageing of GFRP Pultruded Profiles Made of Polyester and Vinylester Resins: Characterisation of Physical-Chemical and Mechanical Damage
}

\author{
S. Cabral-Fonseca*, J. R. Correia ${ }^{\dagger}$, M. P. Rodrigues* and F. A. Branco ${ }^{\dagger}$ \\ *National Laboratory of Civil Engineering, Av. do Brasil, 1700-066 Lisboa, Portugal \\ ${ }^{\dagger}$ Civil Engineering and Architecture Department, Instituto Superior Técnico/ICIST, Technical University of Lisbon, Av. Rovisco Pais I, \\ |049-00 | Lisboa, Portugal
}

\begin{abstract}
This article presents results of experimental investigations of the durability of glass-fibre-reinforced polymer (GFRP) pultruded profiles exposed to typical environments of civil engineering applications. Specimens obtained from commercial GFRP profiles made of unsaturated polyester and vinylester resins were subjected to immersion in (i) demineralised water and (ii) salt water at $20^{\circ} \mathrm{C}, 40^{\circ} \mathrm{C}$ and $60^{\circ} \mathrm{C}$ for up to 18 months, (iii) continuous condensation at $40^{\circ} \mathrm{C}$ for up to 9 months and (iv) accelerated ageing in a QUV chamber for up to $3000 \mathrm{~h}$. The effects of such exposure conditions on both types of profiles were analysed in what concerns their (i) mass changes, (ii) viscoelastic response, evaluated by means of dynamic mechanical analysis (DMA), (iii) mechanical response in tension, bending and interlaminar shear, and (iv) chemical changes, assessed through Fourier transformed infrared spectroscopy (FTIR). Hygrothermal ageing had significant influence on the material performance, namely on the mechanical response - demineralised water immersion caused a higher level of degradation, compared with salt water immersion, and results show a clear competition between moisture-induced plasticisation and residual post-curing of the composite matrix. Following QUV exposure, although considerable aesthetical changes were observed, the viscoelastic response and mechanical performance of both profiles were not remarkably affected, confirming that UV radiation affects essentially the outermost layers of GFRP profiles. In general, the GFRP profile made of vinylester resin exhibited better durability performance, when compared with its polyester counterpart.
\end{abstract}

KEY WORDS: artificial accelerated ageing (QUV), GFRP, hygrothermal ageing, unsaturated polyester, vinylester

\section{Introduction}

In the past few years, the limited durability of civil engineering structures made with traditional materials, such as steel and reinforced concrete, together with their increasing rehabilitation costs, has been promoting the use of innovative materials, among which fibre-reinforced polymers (FRP) in general and glass-fibre-reinforced polymer (GFRP) pultruded profiles in particular are playing an important role $[1,2]$.

Glass-fibre-reinforced polymer pultruded profiles are being used in a growing number of applications, owing to their lightness, high strength, electromagnetic transparency, low maintenance and non-corrodibility. There are already several examples of bridges and buildings comprising GFRP structural elements, in both new construction and rehabilitation of degraded infrastructure [3-5]. These primary structural applications were initially driven forward in the scope of pilot or research projects, but are now finding their own way, in terms of commercial prospect. However, most of the applications of GFRP profiles in civil construction are still concerned with non-structural elements or secondary structures, particularly in industries with specific performance requirements in terms of durability, namely basic sanitation, water and waste treatment plants, navigation ports, petrochemical industry, thermoelectrical plants or railway infrastructure [6].

The already relatively long history of the use of GFRP profiles in the above-mentioned applications, some of which are relative corrosive or environmentally aggressive, provides empirical evidence of their good long-term performance, particularly when compared with alternative mainstream materials. However, comprehensive and validated data on the durability of FRP materials are still scarce, and there is a lack of understanding on the ageing and degradation mechanisms suffered by FRP materials for the different service conditions they are likely to be subjected to in civil engineering applications. In addition, reviews of investigations of the durability of FRP materials [7-9] reveal that test methods can vary considerably, results are sometimes contradictory, experiments under accelerated conditions are performed for maximum durations that are rarely longer than 12 months and only a few studies compared the performance of alternative resin systems. Thereby, because most civil engineering structures are designed for a service life of at least 50 years and reliable degradation models for FRP materials are still to be developed, paradoxically, durability is delaying their widespread use $[7,10]$.

This article presents results of an ongoing experimental study on the durability performance of commercial GFRP profiles made of two alternative resin systems - unsaturated polyester and vinylester - both comprising identical fibre architecture [11, 12]. Specimens from the two types of profiles were subjected to controlled environments, representative of different civil engineering applications, namely immersion in demineralised water and salt water at different temperatures $\left(20,40\right.$ and $60^{\circ} \mathrm{C}$ ) for up to 18 months, continuous condensation at $40^{\circ} \mathrm{C}$ for up to 
9 months, and accelerated ageing in a QUV chamber for up to $3000 \mathrm{~h}$. The performance of both profiles following such exposure conditions was analysed and compared regarding their mass changes, viscoelastic and mechanical responses, and chemical changes.

\section{Experimental Programme}

\section{Materials}

Two commercial off-the-shelf GFRP pultruded rectangular tubes $(50 \times 50 \mathrm{~mm}$, wall thickness of $5 \mathrm{~mm})$ were used in the experimental programme, one made of unsaturated polyester resin (UP profile) and the other made of vinylester resin (VE profile). Pultruded profiles were processed by pulling E-glass continuous fibres with a silane sizing through a bath of resin, at an average speed of $0.25 \mathrm{~m} \mathrm{~min}^{-1}$. The tubular section was produced in a heated die, where temperatures vary between $130{ }^{\circ} \mathrm{C}$ (entrance) and $165^{\circ} \mathrm{C}$ (exit). The profiles present the same E-glass fibre content and architecture comprising two outer chopped strand mats and inner rovings (Figure 1), thereby allowing to compare the long-term performance of both resin systems. With this regard, it is worth mentioning that in applications with no particular durability requirements, unsaturated polyester resin is the most frequently used, while vinylester resin is often chosen in more aggressive or corrosive environments.

\section{Methods}

\section{Exposure environments}

The exposure environments were selected to evaluate the susceptibility to degradation of GFRP pultruded profiles in typical environments of civil engineering applications. In particular, to reproduce the degradation suffered in wet environments, coastal areas and outdoor applications in general, specimens from both types of profiles were exposed to the following environments: (i) immersion in demineralised water - ' $W$ ', (ii) immersion in salt water - ' $S$ ', (iii) continuous condensation chamber - ' $\mathrm{C}$ ' and (iv) QUV
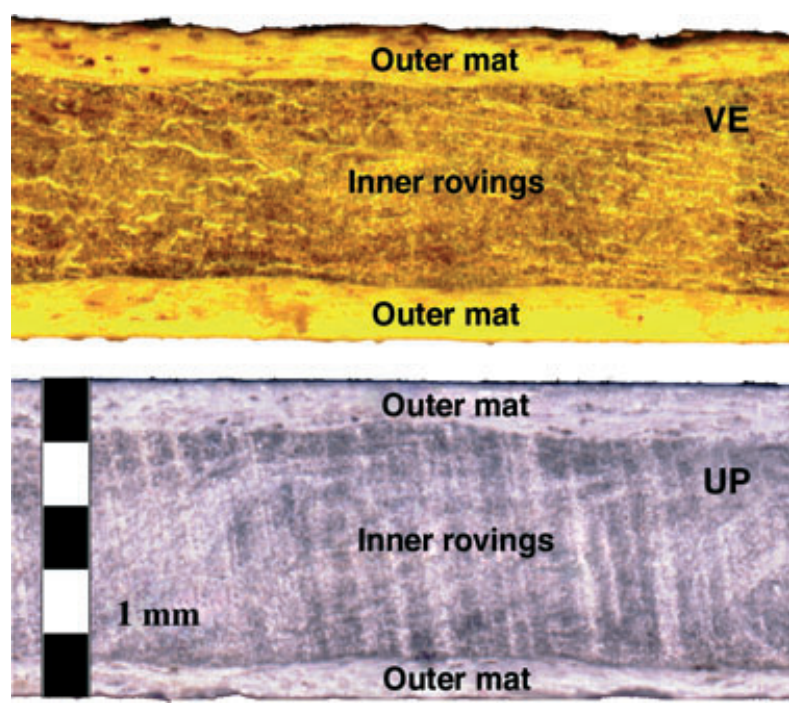

Figure I: Fibre architecture of unsaturated polyester (UP) and vinylester (VE) profiles accelerated weathering fluorescent UV light apparatus 'QUV'.

Immersion ageing in the above-mentioned media was based on ISO 175 [13], and for salt water immersion, the salt concentration (35 $\mathrm{g} \mathrm{L}^{-1}$ of $\mathrm{NaCl}$ ) was defined based on ASTM D 1141 [14]. Immersion was performed at three different temperatures: $(20 \pm 2){ }^{\circ} \mathrm{C}$, as room temperature level; $(40 \pm 1)^{\circ} \mathrm{C}$; and $(60 \pm 1)^{\circ} \mathrm{C}$, as two levels of elevated temperatures, chosen for purposes of accelerating the degradation mechanisms - those temperatures are representative of the highest temperature level likely to be seen during the service life of GFRP profiles used in most civil infrastructure applications.

In the condensation chamber, specimens were exposed to constant condensation of demineralised water at a temperature of $(40 \pm 2)^{\circ} \mathrm{C}$ and relative humidity of $100 \%$, according ISO 6270 - part 1 [15], to study the combined effect of moisture and temperature.

Regarding the QUV chamber, specimens were exposed to repetitive cycles of ultraviolet (UV) radiation and moisture, produced by condensation of water under controlled conditions. The exposure cycles were based on ISO 4892 - part 3 [16] recommendations, consisting of $4 \mathrm{~h}$ of permanent exposure to UV radiation simulated with fluorescent lamps at $60{ }^{\circ} \mathrm{C}$, and $4 \mathrm{~h}$ of exposure to moisture caused by constant condensation of de-ionised water at $50{ }^{\circ} \mathrm{C}$. The fluorescent lamps used in the QUV chamber were UVA-340 type, providing an irradiance of $0.77 \mathrm{~W}$ per $\left(\mathrm{m}^{2} \mathrm{~nm}\right)$ at $340 \mathrm{~nm}$, which reproduces the most relevant part of the sun's spectrum between 290 and $350 \mathrm{~nm}$.

\section{Experimental procedures}

Specimens with appropriate dimensions (for physicalchemical and mechanical characterisation) were cut from the walls of both tubular profiles in the longitudinal direction, using a water-cooled diamond saw blade. After pre-conditioning until constant weight (in a ventilated chamber at $50{ }^{\circ} \mathrm{C}$, without relative humidity control), specimens were exposed to the different ageing conditions.

Durability of both materials was assessed through the evaluation of changes in physical-chemical and mechanical properties during ageing, namely: (i) measurement of mass changes, (ii) assessment of thermo-mechanical performance, (iii) evaluation of mechanical behaviour and (iv) evaluation of chemical changes. Characterisation tests were conducted on each batch of test specimens after predefined time periods: 3, 6, 9, 12 and 18 months for immersion ageing; 3, 6 and 9 months for condensation ageing; and 1000, 2000 and $3000 \mathrm{~h}$ for QUV exposure.

Periodically, test specimens (one for each exposure condition) with a geometry of $(5 \times 15 \times 60) \mathrm{mm}$ were removed from immersion and condensation exposures to evaluate water uptake. The weight gain in each environmental condition was monitored with a $0.0001 \mathrm{~g}$ precision scale before weighing, the superficial moisture was removed by wiping out all specimen surfaces.

Dynamic mechanical analysis (DMA) technique has been used to analyse the viscoelastic response of the materials and to evaluate their glass transition temperature $\left(T_{\mathrm{g}}\right)$, in 
accordance with ISO 6721 - part 5 [17]. Three-point bending type clamp specimens with $(5 \times 15 \times 60) \mathrm{mm}$ were tested at a constant frequency of $1 \mathrm{~Hz}$ and a strain amplitude of $15 \mu \mathrm{m}$, using a Q800 model of TA Instruments (New Castle, DE, USA). The analysis was carried out from room temperature up to $200{ }^{\circ} \mathrm{C}$, at a rate of $2{ }^{\circ} \mathrm{C} \mathrm{min}^{-1}$. Three replicates were tested for each type of material, ageing condition and duration of exposure.

With regard to the mechanical characterisation, both profiles were subjected to tensile tests, flexural tests and interlaminar tests - at least five replicates were tested in the longitudinal direction for each material and ageing condition. It was not possible to perform tensile and flexural tests in the transverse direction because of the limited dimensions of the cross-section of the GFRP profiles. Tensile tests were conducted according to ISO 527 - parts 1 and 5 [18] in rectangular test specimens with $(5 \times 25 \times 300) \mathrm{mm}$ (without end tabs), at a loading rate of $2 \mathrm{~mm} \mathrm{~min}^{-1}$. Threepoint bending flexural tests were performed according to ISO 14125 [19] in rectangular test specimens with $(5 \times 15 \times 150) \mathrm{mm}$, loaded in a $100 \mathrm{~mm}$ span at a rate of about $2 \mathrm{~mm} \mathrm{~min}{ }^{-1}$. Interlaminar shear tests were carried out in accordance with ASTM D 2344 [20] in rectangular test specimens with $(5 \times 10 \times 30) \mathrm{mm}$, loaded in a $20-\mathrm{mm}$ span at an approximate speed of $1 \mathrm{~mm} \mathrm{~min}^{-1}$.

For the chemical characterisation, infrared spectra of aged materials were studied in the $450-4000 \mathrm{~cm}^{-1}$ region, according to ASTM E 1252 standard [21]. For these measurements, powder samples, scraped from the surfaces of test specimens (because chemical changes due to UV radiation occur essentially at the exposed surfaces of the material), were mixed with dry spectroscopic grade potassium bromide and pressed into pellets. Thirty-two scans were collected and averaged at a spectral resolution of $4 \mathrm{~cm}^{-1}$, in a Thermo Scientific Nicolet spectroscope.

Excluding the study of the mass changes, after being removed from the different exposure environments and prior to further testing, specimens were placed inside polyethylene bags. These were hermetically closed, to maintain the moisture content of the material and then placed inside a room with temperature controlled at $20( \pm 2){ }^{\circ} \mathrm{C}$. Prior to testing, specimens were removed from the polyethylene bags and immediately tested without any further conditioning.

\section{Results and Discussion}

\section{Materials characterisation before ageing}

The results of physical-chemical characterisation of both profiles before ageing are listed in Table 1 (average \pm SD values are shown, where applicable).

Spectra obtained by Fourier transformed infrared spectroscopy (FTIR) for both materials were fairly similar. The intensity and localisation of the peaks confirmed the presence of the ester group, as well as aromatic and aliphatic molecular structures, which are common in the chemical composition of both unsaturated polyester and vinylester. Spectra also showed the presence of calcium carbonate, often used as filler, and silica from the glass fibres.

The glass fibre content was determined by the calcination method described in ASTM D 3171 [22], and the density was determined by the immersion method described in ISO 1183 [23]. Those physical properties were slightly higher for the VE profile compared with the UP profile.

Dynamic mechanical analysis results showed that the VE profile glass transition temperature (obtained from both

Table I: Physical-chemical properties of UP and VE profiles

\begin{tabular}{|c|c|c|}
\hline Property & UP profile & VE profile \\
\hline Chemical composition & $\begin{array}{l}\text { FTIR spectra consistent with unsaturated } \\
\text { polyester, with calcium carbonate and silica }\end{array}$ & $\begin{array}{l}\text { FTIR spectra consistent with vinylester, } \\
\text { with calcium carbonate and silica }\end{array}$ \\
\hline Density $\left(\mathrm{g} \mathrm{cm}^{-3}\right)$ & $1.87 \pm 0.11$ & $2.03 \pm 0.05$ \\
\hline Glass-fibre content (\%) & $68.4 \pm 1.8$ & $68.7 \pm 0.4$ \\
\hline \multicolumn{3}{|l|}{$T_{g}\left({ }^{\circ} \mathrm{C}\right)$} \\
\hline$E_{\text {initial }}^{\prime}(\mathrm{MPa})$ & $107.9 \pm 10.8$ & $98.6 \pm 7.0$ \\
\hline $\tan \delta$ & $146.0 \pm 2.3$ & $126.9 \pm 2.38$ \\
\hline \multicolumn{3}{|l|}{ Mechanical properties } \\
\hline \multicolumn{3}{|l|}{ Tension } \\
\hline$\sigma_{\mathrm{t}}(\mathrm{MPa})$ & $406 \pm 31$ & $393 \pm 51$ \\
\hline$E_{\mathrm{t}}(\mathrm{GPa})$ & $37.6 \pm 2.6$ & $38.9 \pm 4.1$ \\
\hline \multicolumn{3}{|l|}{ Flexure } \\
\hline$\sigma_{\mathrm{f}}(\mathrm{MPa})$ & $436 \pm 51$ & $537 \pm 73$ \\
\hline$E_{f}(\mathrm{GPa})$ & $19.8 \pm 2.7$ & $27.5 \pm 4.8$ \\
\hline \multicolumn{3}{|l|}{ Interlaminar shear } \\
\hline$\sigma_{\text {sbs }}(\mathrm{MPa})$ & $38.5 \pm 2.7$ & $39.2 \pm 4.2$ \\
\hline \multicolumn{3}{|l|}{ Compression } \\
\hline$\sigma_{\mathrm{c}}(\mathrm{MPa})$ & $280 \pm 123$ & $360 \pm 131$ \\
\hline
\end{tabular}

FTIR, Fourier transformed infrared spectroscopy; UP, unsaturated polyester; VE, vinylester. 

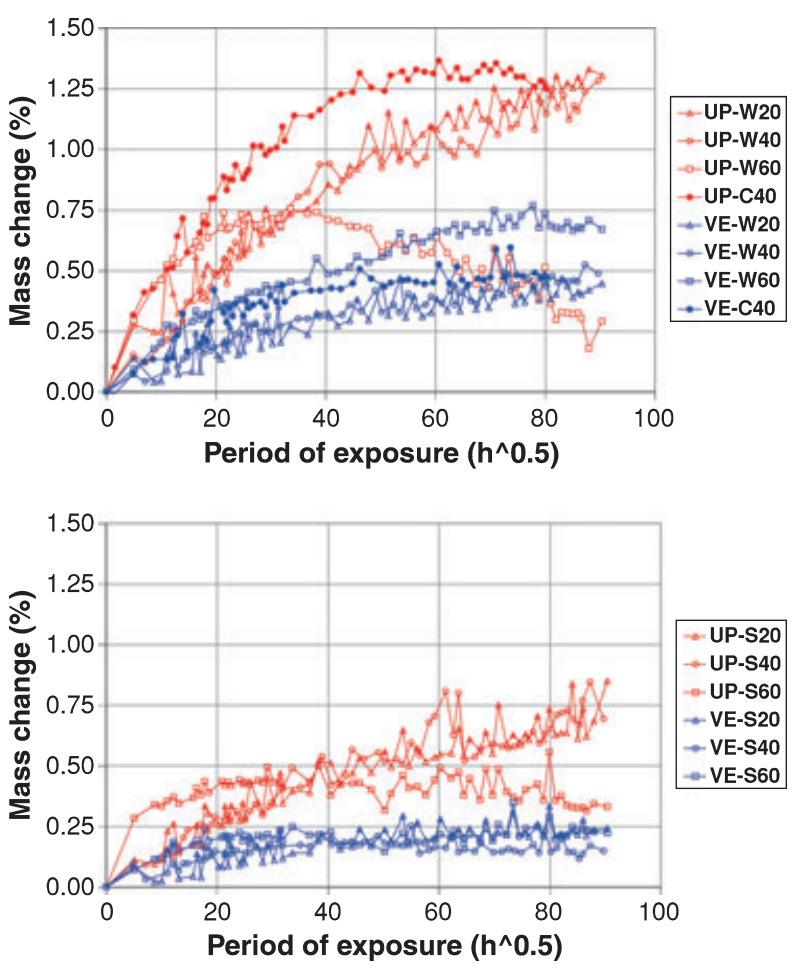

Figure 2: Mass changes of unsaturated polyester (UP) and vinylester (VE) profiles during hygrothermal ageing

the storage modulus and the loss factor experimental curves) was lower than that of the UP profile. From the mechanical point of view, the onset of the storage modulus curves of the UP and VE profiles correspond to temperatures of $108{ }^{\circ} \mathrm{C}$ and $99^{\circ} \mathrm{C}$, respectively - these temperatures set the beginning of a steep reduction in the flexural stiffness of the materials.

In all mechanical characterisation tests, both profiles exhibited a well-defined and typically linear elastic behaviour up to failure. A comparative analysis of the mechanical properties shows that the two profiles are fairly analogous in what concerns tensile properties and interlaminar shear strength; however, the VE profile presents considerably higher flexural properties than the UP profile.

\section{Hygrothermal Ageing \\ Mass changes}

Figure 2 shows the experimental curves of mass variation as a function of the square root of time exhibited by UP and VE profiles for the different immersion media (W for water and S for salt water) and temperatures (W20/S20, W40/S40 and W60/S60 for $20{ }^{\circ} \mathrm{C}, 40{ }^{\circ} \mathrm{C}$ and $60{ }^{\circ} \mathrm{C}$, respectively), as well as for continuous condensation at $40{ }^{\circ} \mathrm{C}$ (C40). Mass uptake in the different ageing conditions showed a response that can be characterised as approximately Fickian. The only exception is the UP profile immersed in water at $60{ }^{\circ} \mathrm{C}$, which started losing mass after $500 \mathrm{~h}$, indicating the leaching out of soluble degradation products stemming from matrix degradation. Furthermore, for similar ageing conditions, there are clear differences in the mass changes exhibited by both profiles (in water, at $20^{\circ} \mathrm{C}$ and $40{ }^{\circ} \mathrm{C}$, the maximum uptake values after 18 months were approxi- mately $1.3 \%$ for the UP profile and $0.5 \%$ for the VE profile), which result from their distinct water absorption capacities, as pointed out by Chin et al. [24]. In fact, moisture diffuses into the polymeric matrix in different ways (in terms of moisture ingress rate, moisture profile throughout the thickness and water uptake capacity), depending upon a number of molecular and microstructural aspects, such as polarity of the molecular structure and degree of crosslinking [25]. Under continuous condensation at $40{ }^{\circ} \mathrm{C}$, both materials exhibited an initial higher weight gain, when compared with immersion in water at the same temperature.

Figure 2 also shows that for both profiles, and for equal temperatures, mass uptake in salt water was always lower than that observed in demineralised water - for example, the mass variation at the end of the exposure period in water and in salt water at $20^{\circ} \mathrm{C}$, which was similar to that at $40{ }^{\circ} \mathrm{C}$, was 1.3 and $0.8 \%$ for the UP profile and 0.5 and $0.3 \%$ for the VE profile, respectively. Previous studies [26] have reported that the presence of salts, such as $\mathrm{NaCl}$, in aqueous solutions results in a saturation reduction, and this trend is clearly observed in the current study. According to Jones [25], the cross-linked matrix acts as a semipermeable membrane where water can permeate, but large inorganic ions are hindered. As a consequence, those ions can operate as osmotic centres.

In addition, it was interesting to observe that the increase in the immersion temperature was not always correlated with the level of mass uptake. This result should be attributed to the mass loss by extraction of low molecular components during immersion, an effect which is expected to increase with temperature. In fact, in these hygrothermal ageing processes, weight changes usually result from a balance between the water uptake because of moisture ingress and the potential loss of material by degradation mechanisms.

\section{Dynamic mechanical analysis after hygrothermal ageing}

Figure 3 shows average DMA curves after 6, 12 and 18 months of immersion in water and salt water for UP and VE profiles. The left axis corresponds to the storage modulus $\left(E^{\prime}\right)$ curves with temperature, which exhibit a characteristic 'step' in the glass transition region; the right axis shows the corresponding loss factor ( $\tan \delta$ ) curves, which present a typical peak in that region. The shape of the storage modulus curves at the transition region reflects mainly the changes in the viscoelastic polymer matrix of the GFRP, which progresses from a glassy state to an elastomeric state, because the glass fibres do not suffer a stiffness reduction in this temperature range.

Figure 4 plots the changes in glass transition temperature $\left(T_{\mathrm{g}}\right)$, determined from the onset of the storage modulus curve decay, as a function of type and duration of hygrothermal ageing.

For the UP profile, an overall trend of decrease in $T_{\mathrm{g}}$ was observed during the initial 12 months of immersion in both water and salt water media, for all temperatures. It can be seen that this period matches with the stage of highest rate of water uptake (c.f. Figure 12). After 12 months, a new 

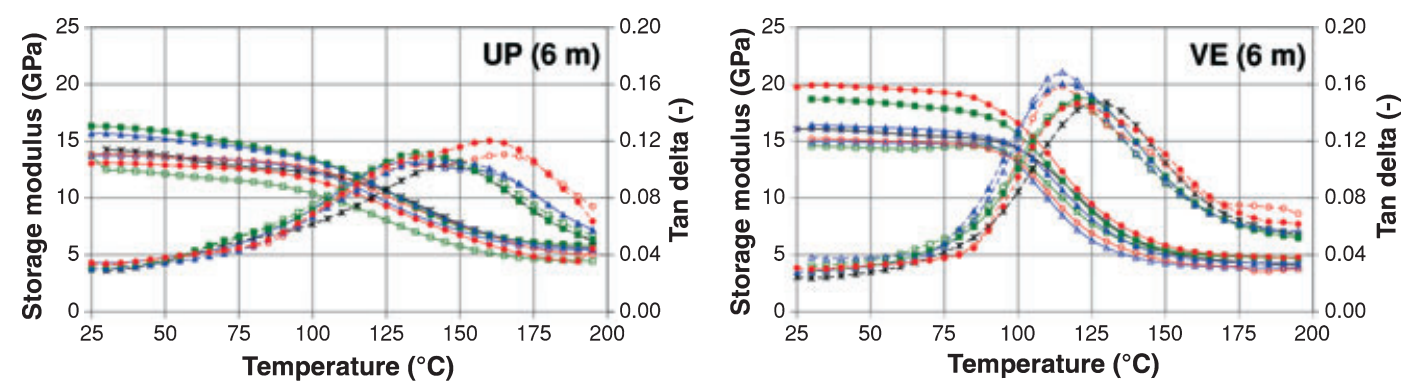

$*$ Un-aged $-\mathrm{W} 20 \div \mathrm{W} 40 \div \mathrm{W} 60 \rightarrow \mathrm{S} 20 \div \mathrm{S} 40 \div \mathrm{S} 60$
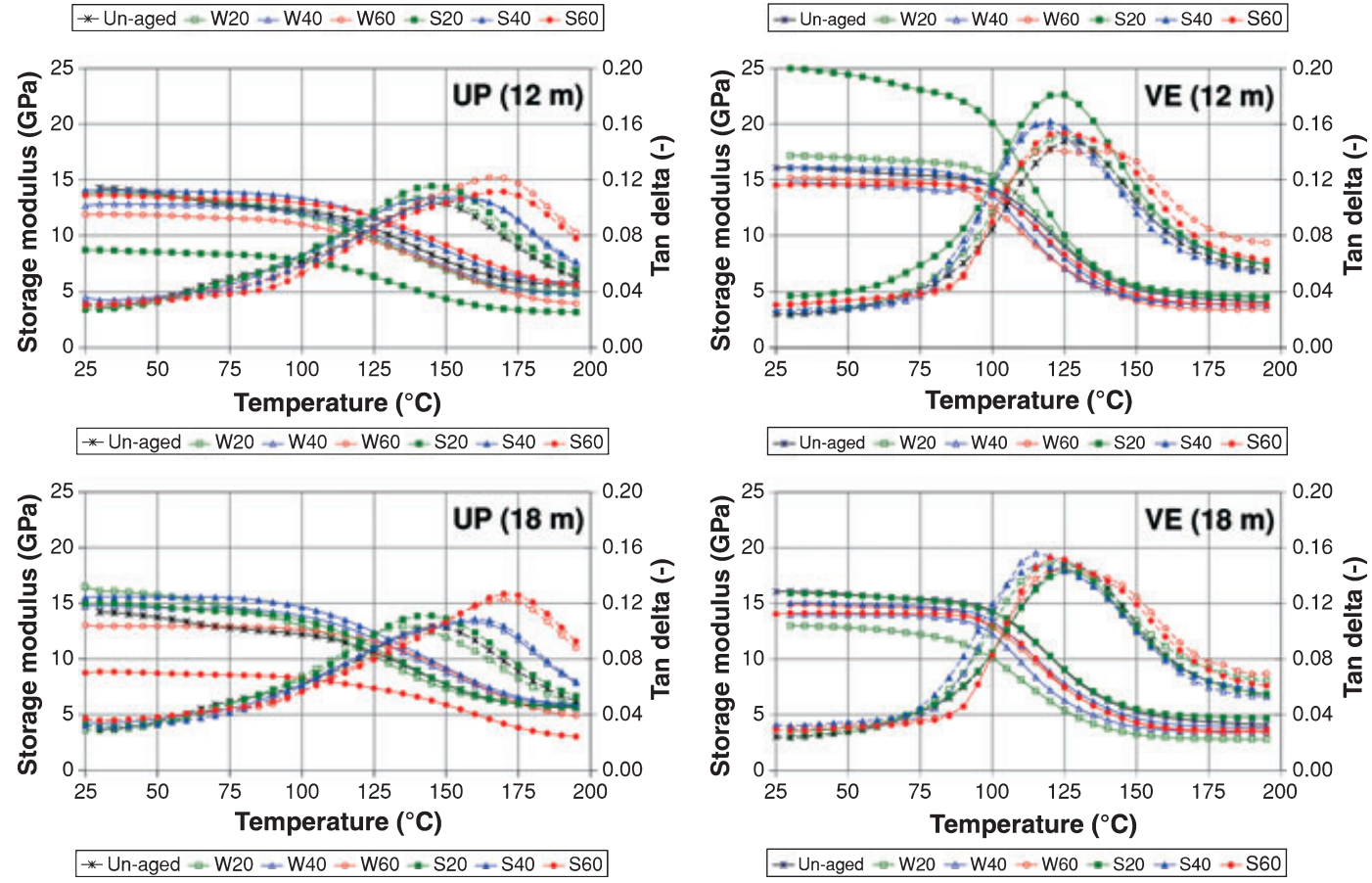

Figure 3: Dynamic mechanical analysis (DMA) curves of unsaturated polyester (UP) and vinylester (VE) profiles after 6, 12 and 18 months of hygrothermal ageing

pattern was observed, as for most conditions, $T_{\mathrm{g}}$ increased with the time of exposure. For immersion at $60{ }^{\circ} \mathrm{C}$, in both water and salt water, the $T_{\mathrm{g}}$ even became higher than that of the un-aged material. According to Berketis [27], one explanation for this inversion of the $T_{\mathrm{g}}$ variation is that during the initial stages of immersion, small fragments acting as matrix plasticisers are leached out causing the main chain to become less mobile in the long term. The fact that such inversion is more pronounced at higher temperatures probably stems from post-curing of the UP resin, as discussed next. The maximum decrease in $T_{\mathrm{g}}$ following water immersion (18\%) and salt water immersion (12\%) occurred after 6 months at $20^{\circ} \mathrm{C}$ - it is worth mentioning that for water immersion, the experimental uncertainty is significant (error bars after 6 months are overlapped with those corresponding to initial characterisation). After 18 months, the levels of retention of $T_{\mathrm{g}}$ were 84,98 and $108 \%$ for immersion in water at $20^{\circ} \mathrm{C}, 40{ }^{\circ} \mathrm{C}$ and $60^{\circ} \mathrm{C}$, respectively, whereas in salt water, those retentions were 95,94 and $111 \%$. The $\tan \delta$ curves of the UP profile after immersion in water at $60{ }^{\circ} \mathrm{C}$ show the widening of the 'peak' base, suggesting that the ageing of the material involves a plasticisation mechanism (resulting from the physical interaction between the polymeric matrix and water molecules, which act as a plasticiser and promote molecular mobility). The occurrence of this widened 'peak' in the $\tan \delta$ curve may be attributed to the different mobility of two kinds of segments in the polymeric matrix, caused by their different extension of plasticisation. The same behaviour was observed for continuous condensation ageing, where the $T_{\mathrm{g}}$ was reduced by $11 \%$ after 9 months.

For the VE profile, the variation of $T_{\mathrm{g}}$ was less dependent from the immersion temperature and, in addition, its variation was less significant than that verified in the UP profile. The tan $\delta$ curves of the VE profile did not show any widening, suggesting that the molecular structure did not suffer significant changes. The only exceptions were the immersions at $60{ }^{\circ} \mathrm{C}$ in both media, in which an asymmetry can be observed in the configuration of the $\tan \delta$ curves, near their maximum value. This result is consistent with the lower water uptake ability exhibited by this material, when compared with the UP profile. After 18 months, the levels of retention of $T_{\mathrm{g}}$ were 89,95 and $96 \%$ for immersion in water at $20^{\circ} \mathrm{C}, 40^{\circ} \mathrm{C}$ and $60^{\circ} \mathrm{C}$, respectively, while in salt water, those retentions were 100 , 96 and $102 \%$. In continuous condensation, the retention of $T_{\mathrm{g}}$ after 9 months was $92 \%$. 

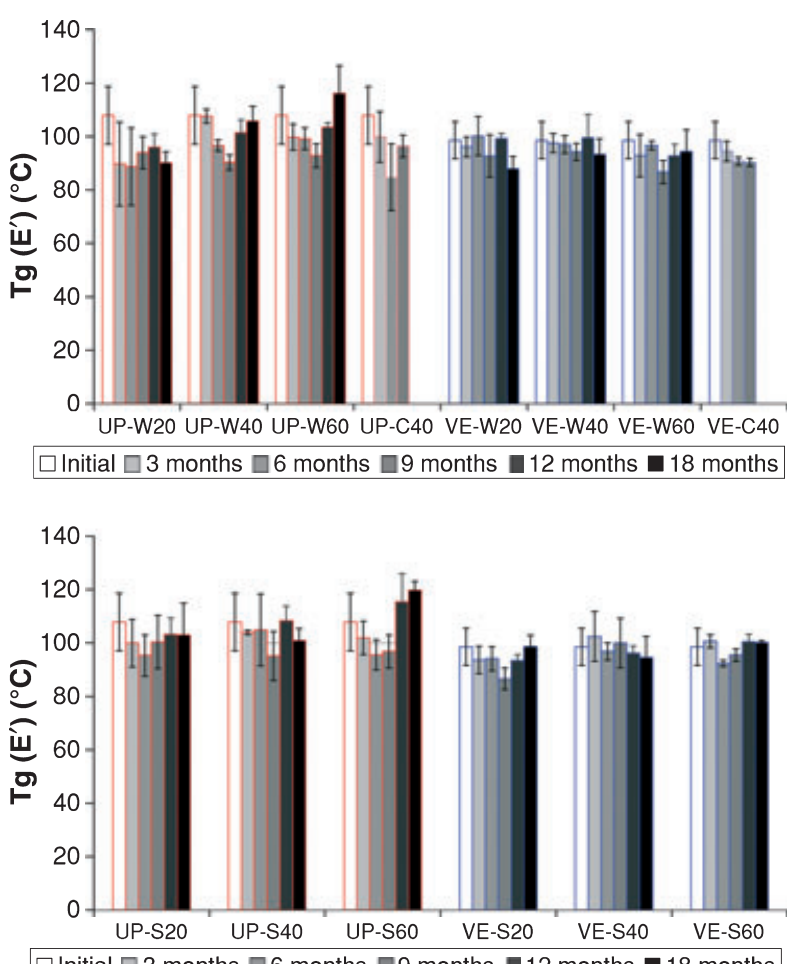

$\square$ Initial $\square 3$ months $\square 6$ months $\square 9$ months $\square 12$ months $\square 18$ months

Figure 4: Glass transition temperature of unsaturated polyester (UP) and vinylester (VE) profiles during hygrothermal ageing

Water uptake by unsaturated polyester and vinylester composites is known to cause plasticisation in the short term and hydrolysis over the long term through attack of the ester linkages [28]. As the ester group is located in the middle of the molecular structure of polyester and at the extremities of the molecular structure of vinylester, the latter resin is more resistant to the above-mentioned plasticisation mechanisms. These phenomena induce higher levels of molecular mobility, resulting in a consequent decrease in the $T_{\mathrm{g}}$, although such decrease can often be offset through residual curing of the resins in aqueous media. These competing phenomena result in fluctuations in the $T_{\mathrm{g}}$ as a function of the exposure period. In the experiments reported herein, such behaviour was shown to be more prominent for the UP resin.

\section{Mechanical behaviour after hygrothermal ageing}

The results obtained in the mechanical tests of both UP and VE profiles, as a function of time and immersion ageing conditions, as well as continuous condensation exposure, are illustrated in Figures 5-7. Those column plots show the average \pm SD (as error bars) values of mechanical properties.

Tensile properties. The tensile strength retention of both profiles as a function of time is plotted in Figure 5 for all ageing conditions. For both profiles, an overall rapid decrease in the tensile strength was observed during the initial 9 months of immersion in water and salt water, for all temperatures - although for some exposure conditions, the differences compared with initial strength are not
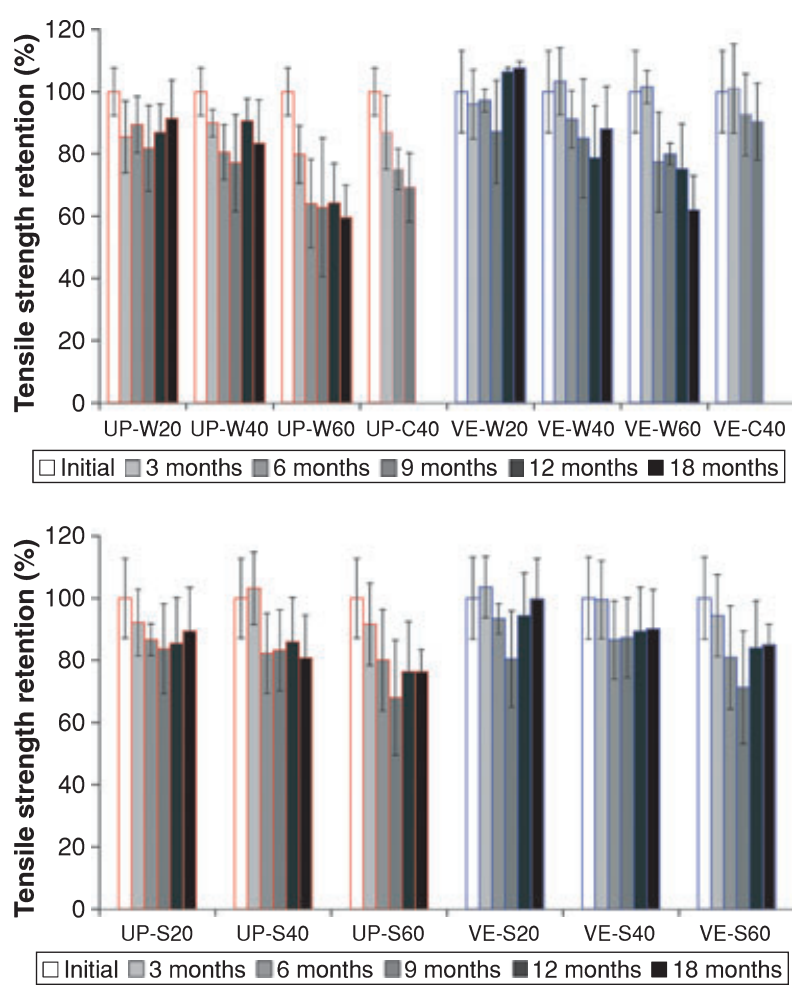

Figure 5: Tensile strength retention of unsaturated polyester (UP) and vinylester (VE) profiles during hygrothermal ageing
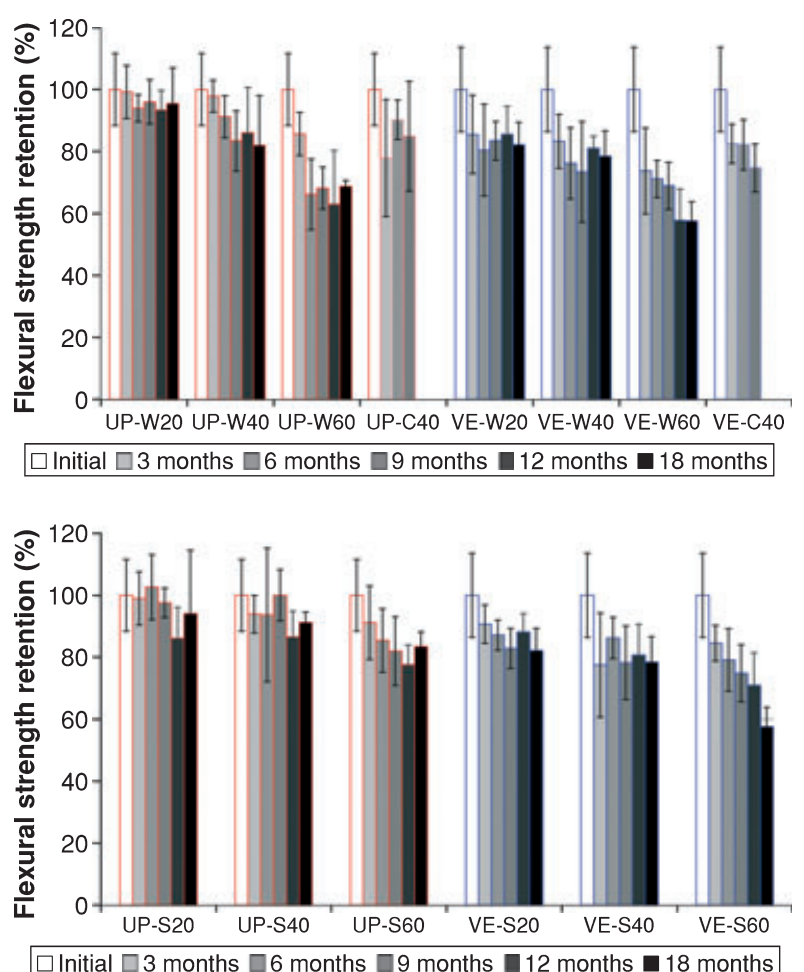

Figure 6: Flexural strength retention of unsaturated polyester (UP) and vinylester (VE) profiles during hygrothermal ageing

outside experimental uncertainty, a general trend of strength decrease is clear in the first 9 months. For continuous condensation at $40{ }^{\circ} \mathrm{C}$, the strength retention was lower compared with immersion in water at the same 

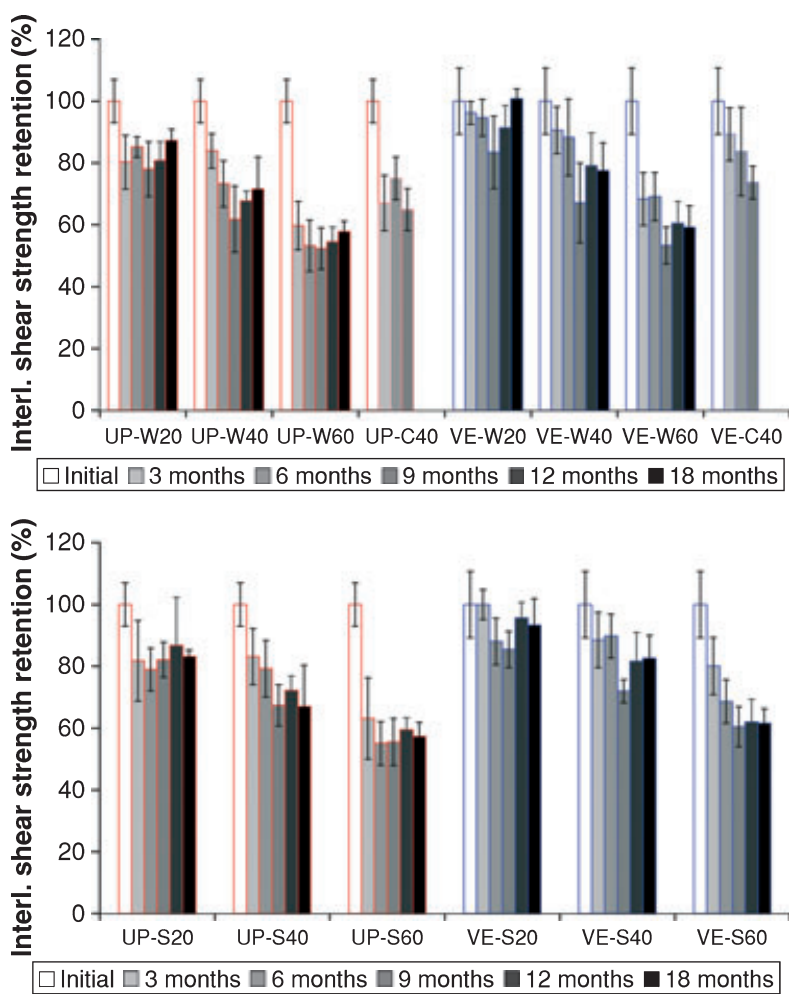

Figure 7: Interlaminar shear strength retention of unsaturated polyester (UP) and vinylester (VE) profiles during hygrothermal ageing

temperature, particularly for the UP profile - this result agrees with the already mentioned higher water absorption capacity exhibited under continuous condensation. For immersion ageing, the initial decrease in tensile strength was generally followed by a trend in stabilisation that took place over the next 9 months, probably stemming from residual curing mechanisms that competed with the plasticisation effect observed initially. For some exposure conditions (e.g. water immersion at $20^{\circ} \mathrm{C}$ for the VE profile), the average strength retentions even increased compared with the initial strength of the un-aged material, and this result has to be attributed to the effects of continuing increase in cross-link density, even though the plasticisation effect initially observed follows the trend earlier identified by Ghorbel [29]. At higher temperatures, the degradation overshadows the effect of residual curing. It is also worth mentioning that those phenomena are less significant in salt water immersion. For the UP profile, the level of degradation of the tensile strength increased consistently with the temperature of the immersion medium, with maximum tensile strength reduction occurring after 18 months in water at $60{ }^{\circ} \mathrm{C}$ (60\% retention). For salt water immersion, the maximum reduction occurred after 9 months at $60{ }^{\circ} \mathrm{C}$ (68\% retention), which was considerably higher than in demineralised water. For the VE profile, the maximum tensile strength reduction occurred after 18 months of immersion in water and after 9 months of immersion in salt water, both at $60{ }^{\circ} \mathrm{C}(62$ and $71 \%$ of retention, respectively). The general higher aggressiveness of demineralised water compared with salt water is consistent with the previous investigations $[30,31]$ and can be attributed to osmotic effects. The variation exhibited by the tensile modulus as a function of the exposure period was less consistent and associated with higher coefficients of variation when compared with the tensile strength, therefore making it more difficult to establish systematic analyses and a consistent comparison between the two profiles. After 18 months of immersion at $20^{\circ} \mathrm{C}, 40^{\circ} \mathrm{C}$ and $60{ }^{\circ} \mathrm{C}$, the UP profile presented tensile modulus retentions of 79 , 89 and $79 \%$ in water, and 83,81 and $81 \%$ in salt water, respectively. For the same exposure conditions, the VE profile exhibited retentions of 96,88 and $93 \%$ in water and 84,100 and $95 \%$, in salt water.

Flexural properties The flexural strength retention of the studied profiles, as a function of time and ageing conditions, is shown in Figure 6. The variation of the flexural properties after continuous condensation exposure was now roughly similar to that observed after immersion in demineralised water at $40{ }^{\circ} \mathrm{C}$. In general, as for the tensile strength, the level of degradation of flexural strength for both materials increased with the temperature of the immersion media, being maximum at $60^{\circ} \mathrm{C}$. Flexural strength degradation in demineralised water was also usually higher than in salt water. It should be mentioned, however, that this behaviour is contradictory with results reported by Liao et al. [32]. In contrast with the behaviour exhibited in the tensile tests (essentially dominated by the fibres), in the flexural tests (also significantly influenced by the matrix and the fibre-matrix interface), strength decrease seems to have occurred more gradually and continuously with the immersion period - a general stabilisation trend can also be identified but without any apparent recovery. For the UP profile, the highest reduction in flexural strength occurred after 12 months of immersion in both immersion media at $60{ }^{\circ} \mathrm{C}(63$ and $78 \%$ for water and salt water, respectively). A higher strength reduction was observed in the VE profile after 18 months of immersion at $60{ }^{\circ} \mathrm{C}$, with $58 \%$ retention in both media. The lower strength retention of the VE profile may be associated with post-curing effects, which must have been more pronounced in the UP resin. Other authors [33] reported also higher flexural strength retention in moulded glass-polyester laminates, compared with glass-vinylester laminates with similar fibre architectures. Regarding stiffness, after 18 months of immersion at $20^{\circ} \mathrm{C}, 40^{\circ} \mathrm{C}$ and $60{ }^{\circ} \mathrm{C}$, the UP profile presented flexural modulus retentions of 103, 97 and $107 \%$ in water, and 95, 102 and 93\% in salt water, respectively. In the same conditions, the VE profile exhibited flexural modulus retentions of 78,92 and $75 \%$ in water, and 93, 92 and $74 \%$ in salt water. As for the tension tests, the variation exhibited by the flexural modulus with the duration of exposure was more irregular and presented higher scattering compared with flexural strength. It is worth mentioning that for some exposure conditions and durations, saturation was not attained. Therefore, residual stresses may have developed throughout the cross-section of the test specimens. In addition, one should also note that flexural strength depends considerably on the local 
behaviour where failure initiates, while flexural modulus is a measure of the global mechanical behaviour of the crosssections.

Interlaminar shear properties. Interlaminar shear strength provides a useful and efficient mean to characterise interface degradation effects. The variation of such property as a function of time and ageing conditions is shown in Figure 7 for the two profiles. Figure 7 shows that the interlaminar shear strength of both profiles exhibits a general trend of reduction with the immersion duration and temperature, and these results seem to agree with those reported earlier by Kharbari [34]. For all conditions, a stabilisation trend can be identified after 12 months of exposure with the highest reductions occurring after immersion at $60{ }^{\circ} \mathrm{C}$, similarly to that observed in the flexural tests. After 18 months of immersion in water, the interlaminar shear strength of the UP profile was very significantly affected, with retentions of 87,72 and $58 \%$ at $20^{\circ} \mathrm{C}, 40^{\circ} \mathrm{C}$ and $60{ }^{\circ} \mathrm{C}$, respectively, while corresponding retentions in salt water were 83,67 and $57 \%$. For the VE profile, the same trend was observed, but with slightly higher retentions - after 18 months of immersion in water at $20^{\circ} \mathrm{C}, 40{ }^{\circ} \mathrm{C}$ and $60{ }^{\circ} \mathrm{C}$ - the retentions were 100,77 and $59 \%$, respectively, whereas in salt water the corresponding retentions were 93, 83 and $62 \%$. The variation of the interlaminar shear strength for immersion in demineralised water at $40{ }^{\circ} \mathrm{C}$ was roughly analogous to that under continuous condensation at the same temperature. The better performance exhibited by the VE profile for all hygrothermal ageing conditions (especially up to $40{ }^{\circ} \mathrm{C}$ ) and periods of exposure is also outlined.

\section{Artificial Accelerated Ageing - QUV \\ Dynamic mechanical analysis after QUV exposure}

Figure 8 shows the variation in both storage modulus and loss factor for UP and VE profiles after exposure to QUVaccelerated ageing during 1000, 2000 and 3000 h. Figure 9 presents, in summary, the variation of the glass transition temperature for both profiles (determined based on the decay of the storage modulus) with the period of accelerated ageing in the QUV chamber.

Figure 8 shows that in general, QUV-accelerated ageing produced little changes in the viscoelastic response of both materials. Although some slight variation was observed in the glassy storage modulus of both profiles, the shapes of the storage modulus and loss factor curves do not present any remarkable changes following QUV exposure. Figure 9 shows that there is a slight increase in the $T_{\mathrm{g}}$ of both profiles, which is consistent with a post-curing phenomenon induced by the UV radiation and the increased temperature - however, such variation is well within the experimental uncertainty expressed by the error bars. After $3000 \mathrm{~h}$ of QUV exposure, the $T_{\mathrm{g}}$ of UP and VE profiles increased 4 and $7 \%$, respectively.

\section{Mechanical behaviour after QUV exposure}

Table 2 summarises the results obtained in the mechanical tests of both UP and VE profiles after QUV exposure, used
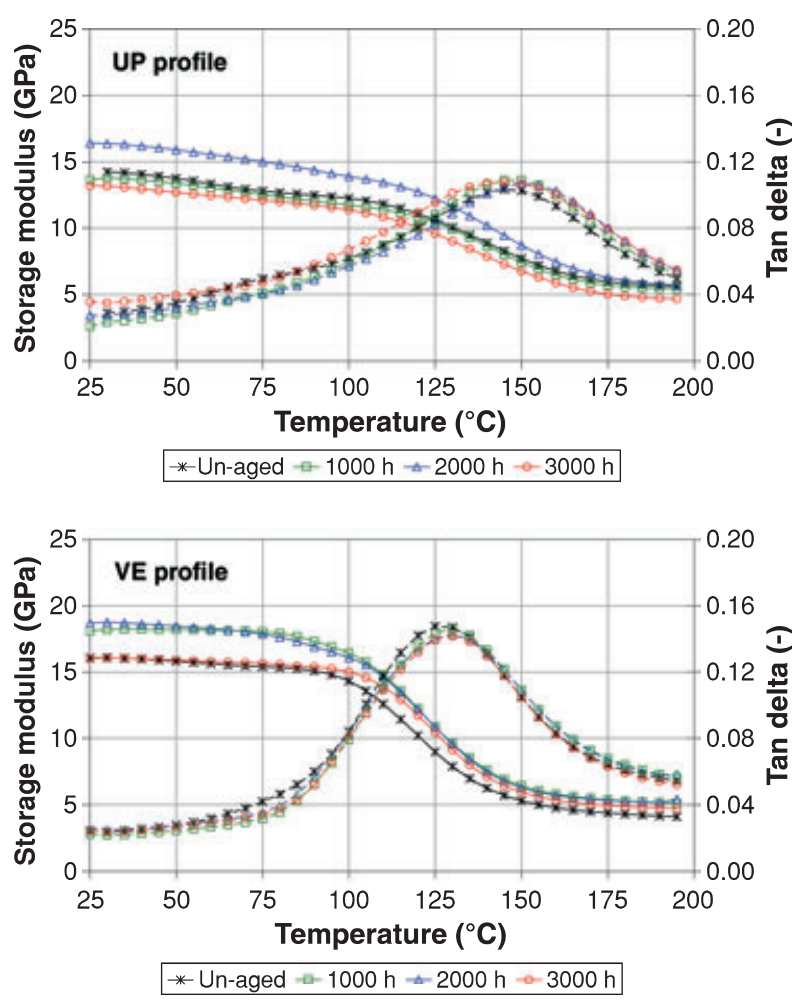

Figure 8: Dynamic mechanical analysis (DMA) curves of unsaturated polyester (UP) and vinylester (VE) profiles during QUV ageing

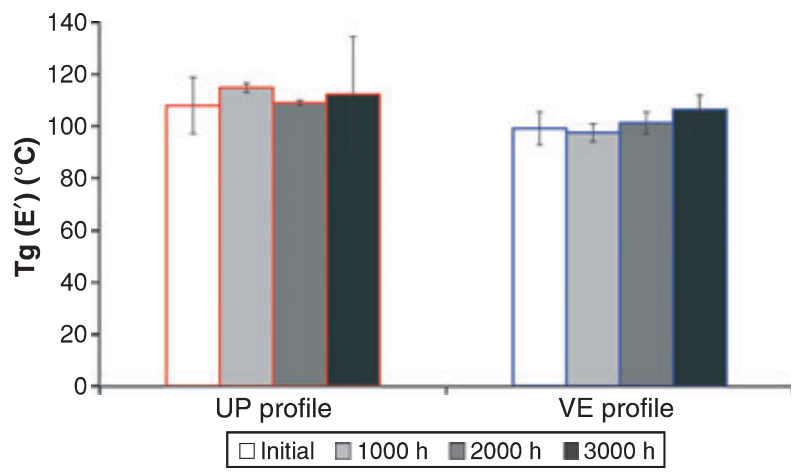

Figure 9: Glass transition temperature of unsaturated polyester (UP) and vinylester (VE) profiles during QUV ageing

to assess the synergetic effects of simultaneous exposure to UV radiation, moisture and temperature in outdoor applications.

Tensile properties The tensile strength retention of both profiles during QUV exposure is shown in Figure 10. It can be seen that the tensile properties of the VE profile were only marginally affected - after $3000 \mathrm{~h}$ of exposure, the strength and stiffness retention were virtually 100\%. In opposition, for the UP profile, it is possible to identify a pattern of reduction in the tensile properties with the exposure period. Although during the first $2000 \mathrm{~h}$ of QUV exposure, there was no considerable decrease in the tensile properties, after $3000 \mathrm{~h}$ of QUV, tensile strength and stiffness retention decreased to as much as 79 and $76 \%$, respectively - however, as for the $T_{\mathrm{g}}$, the experimental 
Table 2: Summary of properties variation suffered by UP and VE profiles at the end of the different exposures

\begin{tabular}{|c|c|c|c|c|c|c|c|c|c|c|c|c|c|c|c|c|}
\hline \multirow[b]{3}{*}{ Properties } & \multicolumn{8}{|c|}{ UP profile } & \multicolumn{8}{|c|}{ VE profile } \\
\hline & \multicolumn{3}{|c|}{ W (I8 months) } & \multicolumn{3}{|c|}{ S (I8 months) } & \multirow{2}{*}{$\begin{array}{l}\text { C40 } \\
\text { (9 months) }\end{array}$} & \multirow{2}{*}{$\begin{array}{l}\text { QUV } \\
(3000 \text { h) }\end{array}$} & \multicolumn{3}{|c|}{ W (I8 months) } & \multicolumn{3}{|c|}{ S (I8 months) } & \multirow{2}{*}{$\begin{array}{l}\text { C40 } \\
\text { (9 months) }\end{array}$} & \multirow{2}{*}{$\begin{array}{l}\text { QUV } \\
(3000 \mathrm{~h})\end{array}$} \\
\hline & W20 & W40 & W60 & $\mathrm{S} 20$ & S40 & $S 60$ & & & W20 & W40 & W60 & S20 & S40 & S60 & & \\
\hline Mass variation (\%) & 1.33 & 1.28 & N.A. & 0.85 & 0.85 & N.A. & 1.36 & N.D. & 0.49 & 0.52 & 0.77 & 0.33 & 0.25 & 0.35 & 0.60 & N.D. \\
\hline$T_{\mathrm{g}}$ retention $(\%)$ & 84 & 98 & 108 & 95 & 94 & III & 89 & 104 & 89 & 95 & 96 & 100 & 96 & 102 & 92 & 107 \\
\hline \multicolumn{17}{|c|}{ Strength retention (\%) } \\
\hline Tension & 91 & 83 & 60 & 89 & 81 & 76 & 69 & 88 & 108 & 88 & 62 & 100 & 90 & 85 & 90 & 100 \\
\hline Flexure & 95 & 82 & 69 & 94 & 91 & 83 & 85 & 113 & 82 & 78 & 58 & 82 & 78 & 58 & 75 & 87 \\
\hline Shear & 87 & 72 & 58 & 83 & 67 & 57 & 65 & 92 & 101 & 77 & 59 & 93 & 83 & 62 & 74 & 93 \\
\hline
\end{tabular}

N.A., not applicable (the behaviour exhibited by both profiles at $60^{\circ} \mathrm{C}$ was not Fickian); N.D., not determined; UP, unsaturated polyester; VE, vinylester.

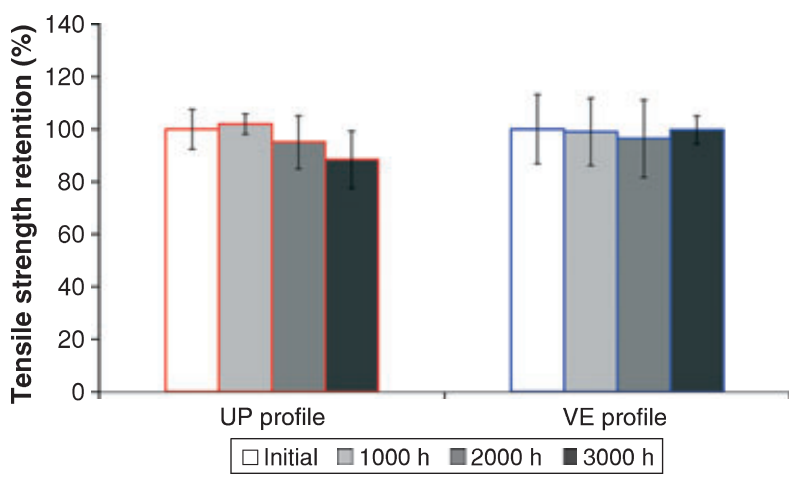

Figure I0: Tensile strength retention of unsaturated polyester (UP) and vinylester (VE) profiles during QUV ageing

uncertainty associated with the above-mentioned variations is quite significant.

Flexural properties. The flexural strength retention of the two profiles during QUV exposure is illustrated in Figure 11. Regarding the VE profile, the flexural strength and stiffness were noticeably affected after $3000 \mathrm{~h}$ of QUV exposure, especially when compared with the variation exhibited by the tensile properties - retentions of 87 and $79 \%$, respectively, were now obtained for those mechanical properties. With this respect, a higher effect of ageing in the flexural tests compared with the tensile tests may be

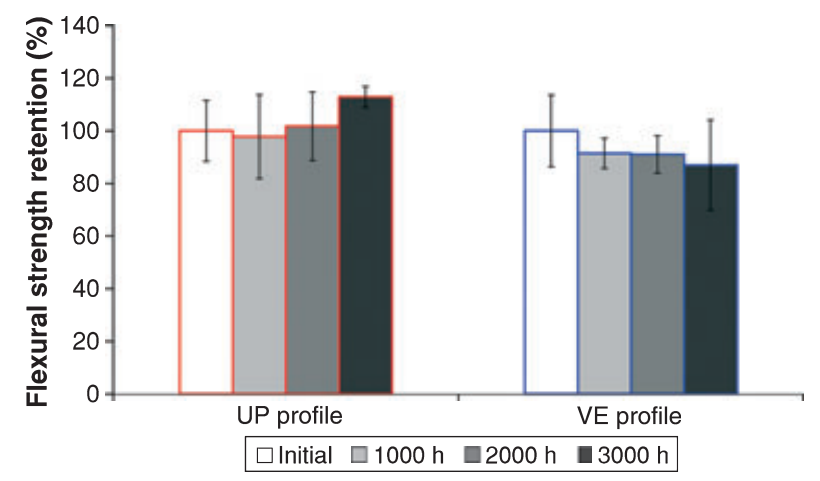

Figure I I: Flexural strength retention of unsaturated polyester (UP) and vinylester (VE) profiles during QUV ageing explained by the fact that in the former tests, the specimen surface exposed to UV radiation was the one subjected to higher tensile stresses, while in the latter tests, the stress distribution throughout the cross-section is approximately uniform. In addition, it must be stressed that the mechanical response in tension depends mainly on the reinforcing fibres, whereas in bending, the role played by the matrix becomes more relevant. In what concerns the UP profile, a slight increase in the flexural strength was observed with the exposure period. The explanation for this result may eventually stem from the effect of postcuring (already reported in DMA tests) caused by the increased temperature inside the QUV chamber and by the UV radiation itself. These results are consistent with experiments described earlier by Correia et al. [35], in which the flexural strength of 10-mm-thick glass-fibrereinforced polyester pultruded laminates was only marginally affected after $6300 \mathrm{~h}$ of QUV exposure.

Interlaminar shear properties. The interlaminar shear strength of both profiles exposed to QUV-accelerated ageing is shown in Figure 12. It can be seen that both profiles suffered a consistent but slight decrease in interlaminar shear strength during QUV exposure. After $3000 \mathrm{~h}$ of exposure, the interlaminar shear strength of UP and VE profiles was only marginally affected, with reductions of 8 and $7 \%$, respectively. This result suggests that the interface

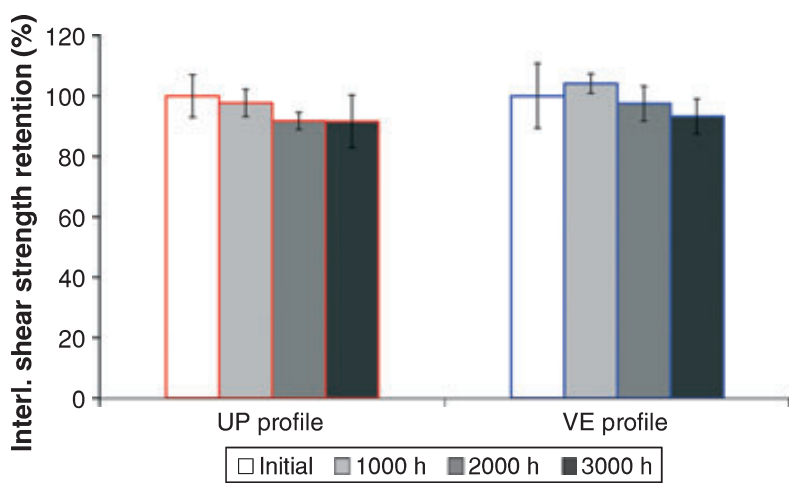

Figure 12: Interlaminar shear strength retention of unsaturated polyester (UP) and vinylester (VE) profiles during QUV ageing 


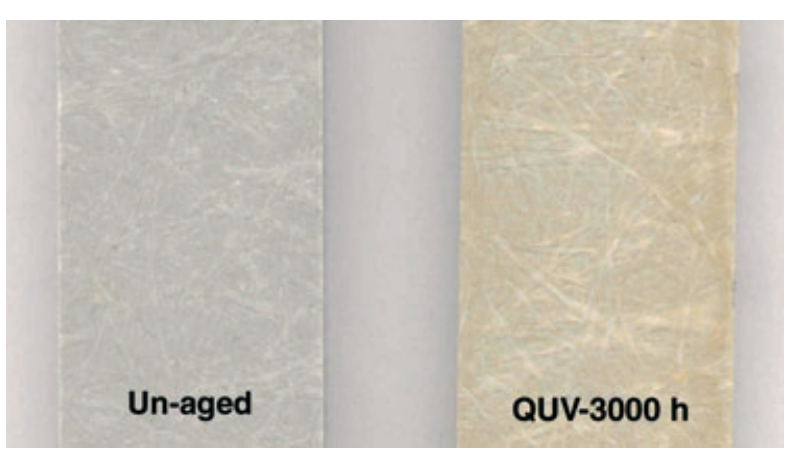

Figure 13: Colour variation of vinylester (VE) profile after $3000 \mathrm{~h}$ of QUV ageing

of both profiles was not significantly affected by QUV exposure.

\section{Chemical degradation after QUV exposure}

After QUV exposure, the colour and gloss of the surfaces exposed to UV radiation were affected - in particular, it was possible to identify a loss of gloss and yellowness in the material surfaces. These changes were particularly evident in the VE profile, which was originally grey (Figure 13). Regarding the UP profile, as it was manufactured with a yellow colour, those visual changes were less perceptible.

In the IR spectra performed on material obtained from the surface of test specimens aged in the QUV chamber during $3000 \mathrm{~h}$ (Figure 14), there is evidence of chemical changes in both UP and VE profiles. Such changes are revealed by modifications in the intensity and in the shape of some peaks. The peak intensity increase at $1636 \mathrm{~cm}^{-1}$, observed in both materials, could be related to the formation of conjugated double bonds $\mathrm{C}=\mathrm{C}$, which explains the yellowness observed in the material surface. The chemical damage mechanism in the surface of the resin, with loss of material, causes some glass fibres to be more directly exposed to the environmental degradation agents. This fact is revealed in the FTIR spectra of the aged materials by the presence of peaks that disclose the existence of silica.

\section{Conclusions}

This article presented results of an ongoing research project on the environmental degradation suffered by GFRP pultruded profiles made of both UP and VE resins, with similar fibre content and architecture, when exposed to environ- mental conditions likely to be found in typical civil engineering applications. Table 2 summarises the most important results obtained in the experimental investigations, in terms of (i) water uptake capacity (maximum variation and diffusion behaviour), (ii) variation in glass transition temperature and (iii) strength retention of mechanical properties. Based on the results obtained, the following conclusions are drawn:

1 The water uptake capacity of GFRP profiles and their temperature dependency is very distinct according to the nature of the polymeric matrix - for similar ageing conditions, the VE profile exhibited considerably lower mass uptake than the UP profile.

2 During an initial stage of hygrothermal ageing, the UP profile presented signs of plasticisation, with a general reduction in $T_{\mathrm{g}}$. However, for longer ageing periods, such reduction was offset because of the occurrence of resin post-curing, particularly at higher immersion temperatures. This increase in $T_{\mathrm{g}}$ could be because of the leaching out of low molecular weight segments, as attested by the mass loss observed at the highest immersion temperature, leading to a more rigid network. For the VE profile, those competing phenomena were less evident, as no fluctuations occurred in the $T_{\mathrm{g}}$ as a function of the period of exposure.

3 Immersion in demineralised water and salt water at $20{ }^{\circ} \mathrm{C}, 40{ }^{\circ} \mathrm{C}$ and $60{ }^{\circ} \mathrm{C}$ as well as continuous condensation at $40{ }^{\circ} \mathrm{C}$ significantly affected the mechanical properties of both profiles - in general, for the different types of loading, after a rapid strength decrease, a stabilisation trend started to be observed. After 18 months of immersion and 9 months of continuous condensation, the strengths of the UP and VE profiles were reduced to as much as 60 and $62 \%$ in tension, 69 and $58 \%$ in bending and 57 and $59 \%$ in shear.

4 Demineralised water was generally more aggressive than the salt water solution and this is because of osmotic effects - as demineralised water is free of solute ions, its molecules can diffuse faster through the GFRP materials compared with salt water.

5 For the majority of hygrothermal ageing conditions and periods of exposure, the tensile and interlaminar strength retentions of the VE profile were considerably higher than those of the UP profile, confirming the
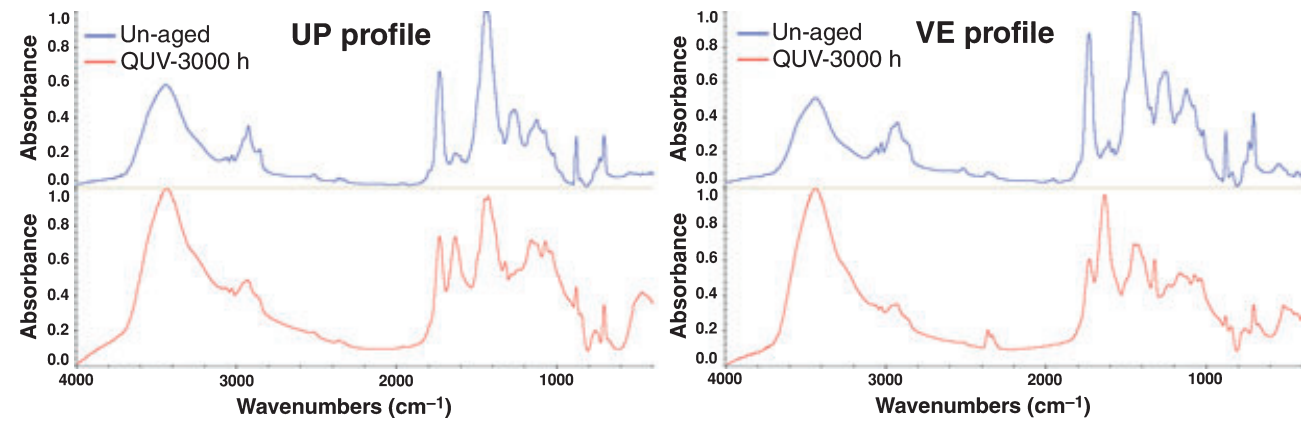

Figure 14: Fourier transformed infrared spectroscopy (FTIR) spectra of unsaturated polyester (UP) and vinylester (VE) materials before and after $3000 \mathrm{~h}$ of QUV exposure 
improved durability performance of the former; in bending, the UP profile presented higher strength retention, but such improved performance most likely stems from post-curing effects, as attested by DMA results.

6 The above-mentioned degradation because of hygrothermal ageing was mainly because of physical degradation phenomena, namely plasticisation of the polymeric matrix, as no appreciable chemical degradation was observed in FTIR $[11,12]$.

7 The effects of artificial accelerated ageing in the QUV chamber on the mechanical properties of both profiles were much less significant compared with hygrothermal ageing. After $3000 \mathrm{~h}$ of exposure, the tensile and interlaminar shear properties of the VE profile were only marginally affected, although a more significant effect was observed in bending, for which strength retention was $87 \%$. For the UP profile, following $3000 \mathrm{~h}$ of QUV exposure, the interlaminar shear strength was practically not affected, but the tensile properties suffered a noticeable reduction, with strength retention of $79 \%$.

8 FTIR showed evidence of chemical changes at the surface of both materials following exposure to UV radiation. Results of FTIR together with results of mechanical tests seem to confirm that the effects of UV radiation are basically confined to a thin superficial layer, causing only a slight reduction in the mechanical properties, especially in tension and shear. Nevertheless, UV radiation causes considerable aesthetical changes, as gloss loss and yellowness, and this should be taken into account in outdoor applications.

As GFRP profiles used in civil engineering applications can be exposed to a broad range of environmental conditions, it is of paramount importance to obtain a mechanistic understanding of their durability performance. The results presented herein provide a better understanding of the mechanisms involved in the ageing of GFRP pultruded profiles - in the next stages of the present research project, the data obtained will be used to develop degradation models, not only to predict property changes with time but also to estimate the remaining service life of GFRP structures.

\section{ACKNOWLEDGEMENTS}

The authors wish to acknowledge the support of FCT, ICIST and Agência da Inovação (Grant No. 2009/003456, Project PONTALUMIS with partners ALTO and University of Minho) for funding the research and also ALTO for supplying the GFRP profiles used in the experimental investigations.

\section{REFERENCES}

1. Bakis, C. E., Bank, L. C., Brown, V. L., Cosenza, E., Davalos, J. F., Lesko, J. J., Machilda, A., Rizkalla, S. H. and Triantafillou, T. C. (2002) Fiber-reinforced polymer composites for construction State-of-the art review. J. Compos. Construct. 6, 73-87.

2. Hollaway, L. C. (2003) The evolution of and the way forward for advanced polymer composites in the civil infrastructure. Construct. Build. Mater. 17, 365-378.
3. Keller, T. (2001) Recent all-composite and hybrid fibre-reinforced polymer bridges and buildings. Prog. Struct. Eng. Mater. 3, 132-140.

4. Keller, T. (1999) Towards structural forms for composite fibre materials. Struct. Eng. Int. 9, 297-300.

5. Sobrino, J. A. and Pulido, M. D. G. (2002) Towards advanced composite material footbridges. Struct. Eng. Int. 12, 84-86.

6. Correia, J. R. (2008) GFRP pultruded profiles in civil engineering: hybrid solutions, bonded connections and fire behaviour. PhD thesis. IST, Technical University of Lisbon, Lisbon.

7. Kharbari, V. M., Chin, J. W., Hunston, D., Benmokrane, B., Juska, T., Morgan, R., Lesko, J. J., Sorathia, U. and Reynaud, D. (2003) Durability gap analysis for fiber-reinforced polymer composites in civil infrastructure. J. Compos. Construct. 7, 238247.

8. Schuttle, C. L. (1994) Environmental durability of glass-fiber composites. Mater. Sci. Eng. 13, 265-323.

9. Liao, K., Schultheisz, C. R., Hunston, D. L. and Brinson, L. C. (1998) Long-term durability of fiber-reinforced polymer matrix composite materials for infrastructure applications: a review. J. Adv. Mater. 30, 3-40.

10. Harries, K. A., Porter, M. L. and Busel, J. P. (2003) FRP materials and concrete - Research needs. Conc. Int. October, 69-74.

11. Costa, R. (2009) Durability of glass fibre reinforced polyester pultruded profiles. MSc thesis (in Portuguese). IST, Technical University of Lisbon, Lisbon.

12. Carreiro, A. (2010) Durability of glass fibre reinforced vinylester pultruded profiles. MSc thesis (in Portuguese). IST, Technical University of Lisbon, Lisbon.

13. ISO 175 (1999) Plastics - Methods of Test for the Determination of the Effects of Immersion in Liquid Chemicals. International Organisation for Standardization.

14. ASTM D 1141 (2008) Standard Practice for the Preparation of Substitute Ocean Water. American Society for Testing and Materials.

15. ISO 6270 (1998) Paints and Varnishes - Determination of Resistance to Humidity. Part 1: Continuous Condensation. International Organization for Standardization.

16. ISO 4892 (2006) Plastics - Methods of Exposure to Laboratory Light Sources. Part 1: General Guidance; Part 3: Fluorescent UV Lamps. International Organisation for Standardization.

17. ISO 6721 (2001) Plastics - Determination of Dynamic Mechanical Properties. Part 1: General Principles; Part 5: Flexural VibrationNon-Resonance Method. International Organization for Standardization.

18. ISO 527 (2009) Plastics - Determination of Tensile Properties. Part 1: General Principles; Part 5: Test Conditions for Unidirectional Fibre-Reinforced Plastic Composites. International Organization for Standardization.

19. ISO 14125 (1998) Fiber-Reinforced Plastic Composites - Determination of Flexural Properties. International Organization for Standardization.

20. ASTM D 2344 (2006) Standard Test for Short-Beam Strength of Polymer Matrix Composite Materials and their Laminates. American Society for Testing and Materials.

21. ASTM E 1252 (2007) Standard Practice for General Techniques for Obtaining Spectra for Qualitative Analysis. American Society for Testing and Materials.

22. ASTM D 3171 (2009) Standard Test Method for Constituent of Composite Materials. American Society for Testing and Materials.

23. ISO 1183 (2004) Plastics - Methods for Determining the Density of Non-Cellular Plastics. Part 1: Immersion Method, Liquid 
Pycnometer and Titration Method. International Organization for Standardization.

24. Chin, J. W., Nguyen, T. and Aouadi, K. (1997) Effects of environmental exposure on fiber-reinforced plastic (FRP) materials used in construction. J. Compos. Technol. Res. 19, 205-213.

25. Jones, F. (1999) Durability of reinforced plastics in liquid environments. In: Reinforced Plastics Durability (G. Pritchard, Ed). Woodhead Publishing Limited, Cambridge, 70-110.

26. Kharbari, V. M., Rivera, J. and Zhang, J. (2002) Low-temperature hygrothermal degradation of ambient cured E-glass/Vinylester composites. J. Appl. Polym. Sci. 86, 22552260.

27. Berketis, K. and Tzetzis, D. (2009) Long-term water immersion ageing characteristics of GFRP composites. J. Mater. Sci. 44, 3578-3588.

28. Chu, W. and Karbhari, V. M. (2005) Effect of water sorption on performance of pultruded $\mathrm{E}$ glass/vinylester composites. J. Mater. Civil Eng. 17, 63-71.

29. Ghorbel, I. and Valentin, D. (1993) Hydrothermal effects on the physical-chemical properties of pure and glass-fiber reinforced polyester and vinylester resins. Polym. Compos. 14, 324-334.

30. Van de Velde, K. and Kiekens, P. (2001) Effects of chemical environments on pultruded E-glass reinforced polyesters. J. Compos. Technol. Res. 23, 92-101.

31. Chu, W., Wu, L. and Kharbari, V. M. (2004) Durability evaluation of moderate temperature cured E glass/vinlylester systems. Compos. Struct. 66, 367-376.

32. Liao, K., Schultheisz, C. R. and Hunston, D. L. (1999) Effects of environmental aging on the properties of pultruded GFRP. Compos. B Eng. 30, 485-493.

33. Kootsookos, A. and Mouritz, A. P. (2004) Seawater durability of glass- and carbon-polymer composites. Compos. Sci. Technol. 64, 1503-1511.

34. Kharbari, V. M. (2004) E-Glass/Vinylester composites in aqueous environments: effects on short-beam shear strength. J. Compos. Construct. 8, 148-156.

35. Correia, J. R., Cabral-Fonseca, S., Branco, F. A., Ferreira, J., Eusébio, M. I. and Rodrigues, M. P. (2006) Durability of glass fibre reinforced polyester (GFRP) pultruded profiles for construction applications. Mech. Compos. Mater. 42, 325-338. 